\title{
ORDENAMIENTO DE TASAS Y DERECHOS DEL MARQUESADO DE VILLENA (1380)
}

\author{
Rogelio Pérez Bustamante
}

Los ordenamientos de tasas y derechos son, junto a los aranceles aduaneros, una de las fuentes, sino la principal, para el conocimiento de la historia del comercio y, por tanto, de la economía medieval, de tal modo que el conjunto de información que este tipo de fuentes ofrece constituye la pieza angular del conocimiento de la propia historia social y económica de su época.

Pero si los aranceles de lezda, peaje, portazgo y hostelaje de la Corona de Aragón correspondientes a los siglos XIII y XIV recogidos por Gual Camarena han permitido reconstruir el mundo mercantil de la Edad Media en aquel territorio', son más escasos los aranceles castellanos y, también, estas otras piezas angulares para el conocimiento de las instituciones económicas y del propio mundo social en ocasiones, que denominamos Ordenamiento de Tasas y Derechos, del cual el que ahora publicamos constituye un elemento de gran utilidad para la reconstrucción histórica del territorio de que se ocupa.

La primera referencia que hemos de hacer en este comentario que sólo pretende servir de introducción al documento es precisamente la de ámbito espacial: el Marquesado de Villena.

Incluido territorialmente en el Reino de Murcia y situado entre las tierras de la Corona de Aragón, del Reino de Valencia, del Arzobispado de Cuenca, del Reino de Castilla y dentro del propio Reino de Murcia al cual, como el documento manifiesta, pertenece, se había constituido como un territorio compacto dotado de personalidad jurídico-administrativa el Señorio de Villena, que durante algún tiempo, como consecuencia de la sentencia de Torrelles, dependiera de Aragón y que posibilita la interferencia de

I Miguel Gual Camarena, Vocabulario del Comercio Medieval. Colección de Aranceles Aduaneros de la Corona de Aragón. s. XIII y XIV. Barcelona 1976. 
este Reino el hecho de que sus grandes señores del siglo XIV, don Juan Manuel y don Alfonso de Aragón, estuvieron familiar e íntimamente relacionados con los señoríos aragoneses ${ }^{2}$.

Las tierras del Marquesado de Villena aparecen integrando la relación de villas y lugares que a principios del XV rendían pleito homenaje a la infanta Maria, hija de Enrique III, entregadas como dote para su matrimonio con Alfonso V de Aragón: Villena, Alarcón, Castillo de Garci Muñoz, Tobarra, Alcalá del Río, Yecla, Iniesta, Sax, Jorquera, Albacete, Ves, Almansa, Hellín, Chinchilla, La Roda, Villanueva de la Jara, Utiel, San Clemente, Munera, Lezuza, Villanueva de la Fuente, el Bonillo y Villarrobledo ${ }^{3}$.

Era pues un territorio fronterizo entre Castilla y Aragón enormemente significado e instrumentalizado en su condición señorial por la propia monarquía a lo largo de toda la época bajomedieva ${ }^{4}$, y según manifiesta Torres Fontes, el conjunto de su territorio tenía una población escasa, excepto algunas villas del Marquesado que alcanzan altas cifras, estando fortificados todos los lugares menos Fortuna y advirtiéndose el asentamiento de una población mudéjar estable que buscaba en ellas mayores facilidades de vida y seguridad para sus personas y bienes.

El «Ordenamiento de Tasas y Derechos del Marquesado de Villena de 1380 » fue otorgado, como manifiesta su documento introductorio, por don Alfonso, hijo del infante don Pedro de Aragón, marqués de Villena y conde de Ribagorza y de Denia, en su condición de titular del Señorío, tras reunir en «ayuntamiento», esto es, en un ayuntamiento general, a todos los procuradores de las villas y lugares del Marquesado con el fin de proceder a una ordenación escrita de aquellas cuestiones que principalmente afectaban a la fiscalidad en el territorio que en aquel momento carecía de «nómina [...] escritura cierta, [...] ordenación de los dichos derechos del dicho almoxarifazgow.

Se trata pues de una acción de gobierno o señorial dirigida según manifiesta don Alfonso, Marqués de Villena, al epro e poblamiento de la dicha mi tierra», es decir, que está establecida para la finalidad de fijar las obligaciones fiscales que en función sobre todo del comercio, se han de pagar en las villas y lugares de aquel territorio, y que posibilitan, por tanto, el conocimiento de las gentes que allí viven, de «los derechos que han de

2 JuAN TORRES Fontes, aMurcia en el siglo XIVm, en La Investigación de la Historia Hispánica del Siglo xn, Problemas y Cuestiones, Barcelona 1973.

3 José M. Soler Garcia, La Relación de Villena de 1575, Alicante 1974, p. 99.

4 Emil .10 Mirre FervínDEZ, «Señorío y Frontera. El Marquesado de Villena entre 1386 y 1402\%, Murgetana, xxx, Murcia 1969, p. 55-62. 
satisfacer» frente al agravio del que habían hecho queja por entender que los almojarifes tomaban y demandaban más derechos que los establecidos por uso y costumbre.

No es éste el primer documento que hasta nosotros ha llegado de don Alfonso de Aragón como marqués de Villena, título que había recibido en las Cortes de Burgos de 1366 de Enrique 11, como denominación nobiliaria del Señorío que correspondía a su esposa Juana Manuel, hija del poderoso personaje don Juan Manuel, que había obtenido de Pedro IV de Aragón la potestad de denominarse príncipe o duque de Villena.

Prueba de este interés organizativo sobre los impuestos indirectos en una tierra calificada por Torres Fontes «de poco rendimiento economicon ${ }^{5}$, es la carta fechada en Ayora el 8 de septiembre de 1377 por la cual don Alfonso ordena a los guardas de las cosas vedadas y diezmeros de Yecla que no cobren diezmos a los de Villena por las bestias que trajeren de Castilla, indicándose que se respeten sus antiguos usos y costumbres y, varios años después, cuando ya se alzaba la sombra de la recuperación del Señorío por la Corona, iniciándose la segregación de algunas villas, el propio marqués de Villena otorgaba em 1393 "Carta de Sentencia» a favor de las gentes de Villena frente al arrendador de los diezmos, de las mercaderías y paños, reconociendo el privilegio de la villa de no pagar diezmo ni tributo alguno sobre tales conceptos ${ }^{6}$.

En el contexto anteriormente citado es por tanto interesante constatar la fecha del citado Ordenamiento de Tasas y Derechos de las villas y lugares del Marquesado de Villena, precisamente de 1380, año en el que según Vicens Vives, se desencadenaba la crisis económica general de Cataluña y la quiebra de los principales bancos de Barcelona, Gerona y Perpignan', y tiempo en el que también se finalizaba la compilación del prímer manual hispano de mercadería".

Probablemente, a las propias exigencias de regulación impresa de las tasas y derechos económicos por parte de los habitantes del Marquesado, se une también la necesidad del propio don Alfonso de Aragón de allegar recursos económicos para mantener su preeminente posición política y cortesana junto al grupo de los parientes del Rey, don Fadrique, duque de

5 Juan Torres Fontes, «Murcia en el siglo XVw, en La Investigación de la Historia Hispánica del Siglo XIV, Problemas y Cuestiones, Barcelona 1973, p. 263.

6 José M. SOler GARCiA, La Relación de Villena de 1575, Alicante 1974, p. 259 y 267.

7 Jaume Vicens VIves, La Ecomomia de los Palses de la Corona de Aragón en la Baja Edad Media, Madrid 1959, p. 23.

${ }^{8}$ Miguel Gual Camarena, El Primer Mamual Hispano de Mercadería. S. xiv, Barcelona 1981. 
Benavente, don Pedro, conde de Trastámara, y don Juan Alfonso de Guzmán, conde de Niebla, tal como aparece al abrirse la minoridad del rey Enrique III en 1390; situación política que le es realmente vital para mantener incluso su propio Señorío, y en tal sentido no olvidemos que, tal como apunta Suárez Fernández, la operación de supresión del Marquesado, aconsejada ya por Pedro Tencrío a Juan I, se hizo posible porque el primogénito, Pedro, murió en la batalla de la Aljubarrota. Se realizó en diversas etapas a lo largo de la década de los noventa del siglo XIV, estando terminada en $1398^{\circ}$.

El Ordenamiento de Tasas y Derechos de 1380 es ante todo una fuente primordial para el estudio de la imposición indirecta, ya que básicamente se trata de los derechos de "Almoxarifazgo», esto es, derechos de aduana y tránsito de mercancía en este territorio fronterizo entre Aragón y Castilla, en cuyos términos, según el documento manifiesta, «avía aduana», y de cuyos aranceles que se tomaban «por uso acostumbrado y albedrío de los almoxarifes» no había «nómina» ni «escrito».

Son fundamentalmente los derechos de almoraxifazgo y otros tributos, tasas y derechos que se fijan en toda la gama de la economía medieval: productos ganaderos, alimenticios, manufactureros, materias primas, circulación de tejidos, paños, cueros de Manises, etc., cuyos derechos de «almoxarifazgo», de «alfadas, de «alquilates, de «jineta", de "cosa movida», «zarpilleras», «montazgo», etc. van apareciendo a lo largo de la especificación de su cobro en los lugares de Villena, Chinchilla, Almansa, Alcalá, Yecla y Hellín.

Junto a todos los productos mercantiles que se comercializan aparece el tratamiento fiscal del comercio de la sal procedente sobre todo de las salinas de Fuentealmilla, Hellín, Orihuela y Jumilla, así como la regulación fiscal de la caza.

Adquiere especial significación el tratamiento fiscal de la población morisca y, desde luego, del derecho de capitulación que se establece sobre los moros y moras.

Ya manifestamos con anterioridad aquella afirmación de Torres Fontes del asentamiento de la población mudéjar estable y, desde luego, a lo largo de este documento se manifiesta el predominio del elemento mudéjar, así como la presencia singular, reiteradamente recogida de los «tártaros y tártaras».

${ }^{9}$ Luts SuÁrez FernÃNdez, Nobleza y Monarquia. Puntos de Vista sobre la Historia Politica Castellana del Siglo XV, Valladolid 1975, p. 85. 
Adquiere, por lo tanto, gran interés el tratamiento fiscal sobre esta población y la reiterada alusión que en el documento se hace a los alcaldes de moros para la solución de sus correspondientes pleitos.

Por último, hemos de subrayar la singularidad del tratamiento que se hace sobre las ferias de Villena, de Chinchilla, de Almansa y de Heflín; las tarifas de las tiendas de «paños, pellería, buhonería, esmerçería e espeçerías; la regulación del tablero de la feria y la prohibición de jugar a los dados fuera de él; del control de la comercialización de los productos que a ella llegan; prohibición de venta encubierta; la protección de las personas, de la paz pública y las ordenanzas sobre circulación de la moneda entre las cuales figura la dobla de oro morisca. 


\section{ANEXO}

1380, abril, 6. Almansa

Carta de Alfonso de Aragón, Marqués de Villena y Conde de Ribagorza y Denia otorgando un Ordenamiento sobre las tasas y Derechos que hablan de pagarse a las villas y lugares del Marquesado de Villena. (En traslado de $\mathbf{9}$ de octubre de 1413.)

\section{A. D. FRIAS.}

En el nonbre de Dios sea amen. Sepan quantos esta carta vieren e oyereen como nos Don Alfonso fijo del infante don Pedro de Aragon, - Marques de Villena e conde de Ribagorça e de Denia yo mande por mis cartas a los cavalleros e escuderos del mi Marquesado e a todos los conçejos de todas las villas e lugares del dicho mi Marquesado que enbiasen sus procuradores aqui a la mi villa de Almansa para el primero dia de Abril en que agora estamos por ordenar algunas cosas en la dicha mi tierra que fuesen en serviçio del Rey e mio e pro e poblamiento de la dicha mi tierra. $\mathrm{E}$ - estando ayuntados conmigo los dichos procuradores en la dicha villa de Almansa con el acuerdo e consejo dellos he ordenado muchas cosas entre las quales ordene que por razon que en todas las mis villas e logares del dicho mi Marquesado que yo he en el regno de Murçia en cada una dellos e - sus terminos avia aduana e su paga en ellos e en cada uno dellos e sus terminos almoxarifazgo e veyntena e portadgo e erbage e montazgo e otros derechos e como destas cosas en toda la dicha mi tierra e logares del dicho mi Marquesado del dicho regno de Murçia non ay nomine ni otra escriptura çierta ni otra ordenaçion a lo qual como se de $-f^{\mathrm{p} 2}$ ven coger los dichos derechos del dicho almoxarifadgo salvo que se cogian fasta aqui por uso acostumbrado e por alvedrio de los almoxarifes que fasta aqui lo an cogido, por lo qual los que los dichos derechos pagavan entendian seer-agraviados ellos e porque dixen que los almoxarifes que cogían los dichos derechos en los dichos logares e sus terminos e en cada uno dellos los tomavan por ellos e los demandavan mucho mas de cuanto avian a dar e de pagar e los ofiçiales que esto a tal avian e han de librar e de judgar en - los dichos lugares en cada uno dellos cada que ge lo querellaban - non se atenian a lo librar esto por quanto non avia nomina e declaraçion çierta dello como dicho es e yo por quanta esta dubda fiz e mande fazer sobre ello esta declaraçion e ordenamiento como se cogia el dicho almoxarifadgo e en cada lugar e en su termino de aqui adelante los almoxarifes que lo ovieren de coger por la manera que aqui dira e que sea dado a cada lugar su ordenaçion e declaramiento dello signado de escrivano publico con autoridad de alcalde sacado el qual mande sellar con mi sello e lo firme de mi nonbre el qual fue fecho en la mi villa de Almansa seys dias de Abril era de mill e quatroçientos e diez e ocho años.

Primeramente en Villena las tierras del pan e los fornos e las salinas e el pynar son del almoxarifadgo.

$F^{3}$ Estas son las cosas que los barranos que vernan a vender e a conprar algunas cosas de mercadurias e otras cosas a la villa de Villena e a su termino que han de pagar dello veyntena de todas cosas salvo ende de pan e de vyno e de pescado fresco que se venda para perjuiçio de la dicha villa pero los que vendieren e conpraren el 
dicho pan e vino e pan e pescado a omes de fuera de Vyllena e a verinos della quel barrano que sea tenudo de pagar veyntena de lo que desta gisa vendiere e conprare para lo llevar fuera de Villena como dicho es.

Otro si si fuere moro o mora quier sea veçino de Villena quier non, que page alquilate de toda cosa que vendiere o conprare en qualquier manera que sea que es el derecho del alquilate de lo que vendiere $\mathrm{e}$ conprare segund dicho es de doze maravedis un maravedi e a este respey to de lo que vendiere e conprare segund dicho es, segund mas o menos en Villena e su termino.

Otrosi han de pagar mas los dichos moros de Villena otro derecho que llaman alfarga que es de cada carga mayor o menor de pescado fresco o salado e los de fuera della tanbyen una libra,

Otrosi los dichos moros e moras han depagar de cada año de cada cafiz de quanto pan vendieren un çelemin.

Otrosi pagan mas los dichos moros de Villena casados o viudos cada año por cada una cabeça seys sueldos e dos dineros e sy es moço de hedad paga çinco sueldos e quatro dineros e las moras o mora viudas deste derecho non pagan cosa alguna.

$F^{+}$Otrosi pagan mas los dichos moros de Villena de alfarda de cada un año quinientos maravedis.

Otrosi pagan mas los dichos moros e moras de Villena de cada año de almoxarifadgo trezientos maravedis, los quales dichos trezientos maravedis fueron estableçidos a las capellanias de San Gines del Canpo, esto por quanto los capellanes de San Gines los toman en los fornos de Chinchilla.

Otrosi pagan mas los dichos moros e moras de Villena otro derecho que llaman alfarga de cada año que es de cada casa el moro que es señor de la casa por su cabeça, çelemi e medio de çevada e la muger de aquel e fijos e fijas e moços e moças e otras personas qualesquier que estovieren en la dicha casa pagan por cada una cabeça un çelemin de çevada.

Otrosi pagan mas los dichos moros de Villena de cada año otro derecho que es de potros e de muletos e muletas e bezerros e pollynos de cada uno destos de cada año quando naçen, pagan dos maravedis e de ganado menudo de cada cabeça dos cornados.

Otrosy sy algunos moro o mora moviese syn herederos los sus bienes de los que desta guisa moriere son e pertenesçen al almoxarifadgo e los moros e moras que desta guisa moriesen, el alcalde de los moros nin los viejos non sean osados de entrar en las casas de los que desta guisa moriesen por sus $f^{5}$ bienes ni por los tomar syn estar presente a ello el almoxarife que oviere de aver el almoxarifadgo e sy el dicho allcalde e viejos o qualquier dellos o otro alguno moro syn el dicho almoxarife tomase los dichos bienes o algunos dellos e los fiziesen de los y muriese en la manera que dicho es que los que esto fizieren asy el dicho alcallde como los dichos viejos o qualquier dellos o otro moro alguno que ellos e sus bienes dellos son e sean confiscados a la renta del dicho almoxarifadgo.

Otrosi sy algunod moro o mora fixiese algunas cosas por donde merezca pena de açotes o de daños sea juzgado por su alcallde moro seyendo presente el almoxarife e sy el moro o mora que en tal pena cayere sy se abiniese con el almoxarife que lo pueda fazer e que sean quitos de la dicha pena. 
Et sy algunos moros o moras viniesen deotra parte a la villa de Villena a morar a ella escondidamente e se non es e publica en poder del almoxarife son perdidos ellos e sus bienes e son del almoxarifadgo.

Otrosi qualquier moro o mora de los vezinos de Villena que se fueren a morar a otra parte fuera del señorio del dicho señor Marques e non levasen carta de como han pagado todos los derechos que pertenesçen al dicho almoxarifadgo e sy despues las sus personas dellos fuesen tomadas sean catyvas del almoxarife e sus bienes destos a tales son del almoxarifadgo.

$1^{10} 6$ Otrosi qualquier persona que sea que troxiere qualquier cosa a vender en Villena que se deva pagar della derecho que pertenesca al almoxarifadgo que lo descarge en la plaça e que lo non meta en casa alguna fasta que lo vea el almoxarife e le de liçençia que lo meta, en la casa donde oviese de posar, e la mercaduria ensiese en la posada antes que lo manifieste al almoxarife que lo pierda todo por descaminado, e el huesped que a este a tal acogiese en su casa con la mercaduria antes que aya liçençia del almoxarife y pague de pena sesenta sueldos.

Otrosi qualquier persona de tierra del reyno de Aragon o del Obispado de Cuenca que entrare a ervajar a termino de Villena e de Sax con ganados cabrio o lanar e pague por ello al almoxarife del Marquesado montadgos por quatro sueldos por çiento por todo el año quier lo cunpla quier non, e de bueyes e devacas e de yeguas que sean solariegas que pague por cada una cabeça un maravedi.

Otrosi pagan mas los dichos moros de Villena por el puerto de Sax e por el alquilate e dende por la merçed quel dicho señor Marques les fizo dello de cada año trezientos maravedis.

Otrosi en fecho de la sal por quanto todos los veçinos e moradores en Villena tyenen libertad que puedan fazer de cada año cada uno en cada casa un cafiz de sal syn preso alguno dar por ella ef ${ }^{77}$ non pueda fazer mas e sy dese dicho cafiz de sal que han de fazer de cada año como dicho es e non puedan vender ninguna cosa del a ninguna persona $\mathbf{e}$ sy lo fiziese, el que esto fizyese e por cada una vegada que lo fiziere e peche sesenta sueldos al almoxarife.

Pero qualquier persona del dicho lugar de Villena que conprare del almaçen treynta o quarenta cafiçes de sal o mas o menos que los pueda vender a los que quisiere syn pena alguna al presçio que bien visto le sera.

Otrosi quel que toviere el dicho almaçen de la dicha sal de Villena que toda la sal que menester oviesen los veçinos de Villena e de Almansa e de Yecla, que den epagen por cada un cafiz de sal, seys sueldos e que ge la non puedan negar de mientre que la oviere nin les puedan demandar mas presçio de los dichos seys sueldos por cada cafiz so pena de sesenta sueldos, la meytad de la dicha pena sea para la camara del dicho señor Marques e la otra meytad para el acusados della

Otrosi los dichos conçejos de los dichos lugares de Villena e de Almansa e de Yecla e los veçinos de los dichos lugares non puedan traer sal alguna de otras partes salvo del dicho almaçen de Villena e sy alguno o algunos veçinos de los dichos lugares troxieren sal deotras partes salvo el dicho almaçen de Villena $f^{\mathrm{P}}$ que caygan en pena cada uno por cada una vegada que esto fixizeren, de seysçientos maravedis al almoxarife e esto que se entyenda aviendo sal en las salynas de Villena e non en otra manera, pero que sy el almoxarife se reçelare que algunas personas de los veçinos de los dichos lugares e decada uno dellos han metido alguna sal de fuera como dicho es, que pueda entrar en escodrinar las casas que avra sospecha que lo 
pueda fazer con un ofiçial de la dicha villa e sy tal sal les fallare que les pieda levar la dicha pena de los dichos seysçientos maravedis.

Otrosi sy sal alguna queda al arrendador del año pasado e despues el que arrendare 1 otro año si las salinas que pueda tomar sy quesiere el cafiz de la sal que desta guisa fallare a tres sueldos por cada un cafiz.

Otrosi quando se faga la feria de Villena lo que pertenesçiere al almoxarifazgo en ella es esto, primeramente el tablero e sy tyendas de paños se paran en ella an de cada tyenda diez sueldos, e sy fuere una pieça de paño fasta en dos o en tres o quatro pagan de cada pieça um sueldo e de la tienda della pelleria e buhoneria e esmerçeria e espeçeria, pagan de cada tienda çinco sueldos por sy alguno pasare tyenda de espeçeria e de buhoneria e de esmerçeria que trayga a cuestas este derecho pertenesce al alguazil de la feria e sy en la dicha feria de Villena se non pagaren treze tiendas $f^{\circ 9}$ asy de cuello como de otras que fasta treze tyendas asy de cuello como de bestias que sean todas del almoxarifadgo e quel alguazil non aya nada dellas, e sy treze tyendas toviere de bestias o mas, que sean todas del almoxarifadgo e las tyendas de cuello e de cuestas deomes que sean todas del alguaçil de la feria de Villena.

Otrosi qualquier persona que fuere fallada judgando los dados fuera del tablero de laferia del tablero de Villena que cayga en pena al almoxarife cada uno por cada vegada, de sesenta sueldos e sy en alguna cosa jugaren encubiertamente, syn voluntad del almoxarife quel señor de la casa donde jugaren de la manera que dicha es, que cayga en pena de otros sesenta sueldos.

Otrosi de lo que viene a Villena en la feria como nuezes o castañas e bellotas e almendolas e todas legunbres e frutas semejantes desto a el almoxarife de parada de cada carga un çelemin e sy non oiyere carga conplyendo de qualesqujer destas cosas sobre dichas que paguen al respleyto de la carga.

Otrosi la dicha feria de Villena es franca de veyntena de todas cosas que se vendieren e conprasen en ella, asi cristianos como judios e moros e moras, los moros son quitos de alquilate en toda la dicha feria.

Qualquier persona que vendiere paños o otras mercadurias $f^{\mathrm{f}} 10 \mathrm{o}$ otras cosas encubiertamente o las conprasen e lo non sacasen a la feria que lo pierdan por descaminado e sea todo del almoxarifadgo.

Otrosi qualquier que vendiere en Villena e su termyno cavallo o armas o conprare que sea barrano, pague veyntena dello e los moros alquilate al almoxarife.

Otrosy sy algun moro o mora se desfierra e ataja en Villena o termino o tartado o tartara en su termyno a el almoxarife de todo lo que se atajare o rindiere el diezmo dello e mas syn esto una dobla de oro morisca aun que sea de feria.

Otrosi todas las otras cosas que aqui non son escriptas ni ordenadas como en raçon de los moras que son ferradas que a Villena e a su termino que de e page cada una dellas el dicho sienpre acostunbrado de pagar e eso mesmo de todas las otras cosas que aqui non son escriptas ni ondenadas que pagen por ellas e por cada una dellas lo que han acostunbrado de pagar aquel o aquellos que han de derecho porque los pagan.

Otrosi ordeno el dicho señor Marques en razon de las cosas movidas que se non page en todo su marquesado mas de una cosa movida e que la page en el primero lugar que llegare e que tome alli del almoxarifadgo o portadgo que coge los dichos derechos alvala de como pago ally la $f^{11}$ la dicha cosa movida e lo non 
tomen nin pagen mas en todo el su marquesado por la dicha cosa movida sy non una vez.

Otrosi ordeno el dicho señor Marques en razon del fecho de que se fazen en los dichos lugares e sus terminos del dicho su marquesado porque algunas personas fazen encubyertamente algunas vendidas e conpras entre si por absençia del derecho del dicho almoxarifadgo el almoxarife que esto oviere de aver e de recabdar oviere sospecha que van vendidas o apalabradas o conpradas algunas mercadurias o ganados o otras cosas a persona o personas de quien el deve aver el derecho del dicho almoxarifadgo dellas que les faga fazer jura que no van vendidas ni conpradas ni apalabradas nin fecho algund presçio por ellas e en ellas e faziendo la dicha jura e que la faga asy el veçino como el barano porque deste fecho se sepa la verdad e sy dixiere que non que sea quanto del dicho derecho e sy dixiere que sy, que sea todo descamynado e del almoxarifadgo.

Otrosi si algun moro e mora pusiere querella antel alcallde moro de otro moro o mora tal querella pusiere que sea tenudo de lo mantener e ge lo levar en adelante e sy lo non fiziere la querella puesta que se pare en la pena en la pena el que pusiere la dicha querella que merescia aver aquel contra quien fue puesta la dicha querella de la cosa que querellare seyendo puesta.

En Chinchilla se coge desta gisa primeramente de portadgo alaçon, çerda, paños, valvagina, espeçeria, buhoneria, $f^{P}$ esmeçeria, e ajos e vinagre, seda, algodon, asoge, toda adobada paga todo esto por çerrado es a saber carga menor, quatro maravedis, e carga mayor seys maravedis e carga de unto e de cueros e de sevo paga por medio çerrado carga mayor tres maravedis e cargamento dos maravedis de tierra de manses e en troço e lana e toçino e alfonbras e tapetes e filos e babon c esteras e palmitos e pastel e tyntas e pasa e figos secos e pescado salado e congrio e sardina e todo otro pescado salado e limones e todas estas cosas e otras semejantes destas pagan todas por castellano es a saber por carga menor quinze dineros e por carga mayor dos maravedis e carga de a toda fruta verde e de naranja e de vyno pagan por carga valady e es por la carga mayor un maravedi e por carga menor siete dineros e medio. Otrosi quando el rey faze graçia a alguno que saquen algund pan en Aragon a de pagar al almoxarife de cada carga tres maravedis.

Otrosi de las bestias çerriles que se pagan por vender muletos e muletas asy çerriles como de albarda que pagen de portadgo de cada uno seys maravedis e del asno e asna de cada una quinze dineros.

Otrosi del moro e de la mora que por Chinchilla pasare a de $f^{P 13}$ pagar cada uno una dobla de oro morisca de portadgo e sy se rindiere ally e se desfierra ally que lo levare a Murçia o a otra parte o a tierra de moros pagan por cada uno una dobla de oro morisca por el desferro e otra dobla de portadgo e mas syn esto el diezmo de toda la quantia porque se rendiere.

Otrosi el almoxarifadgo de Chinchilla se ha de coger e coge desta guisa de todas las cosas que se conpraren e se vendyeren en la dicha Chinchilla e su termino pagen veyntena de veynte maravedis uno salvo ende de pan e vyno e carne muerta fresca e salada e de pescado fresco que se vendiere todo esto por menudo e de todas legunbres pero que el almoxarife a los que omiten de pagar las dichas cosas de la vendida o de la conpra por quel almoxarife que se atenga a lo que mas mostrare.

Otrosi de todos los moros e moras que troxieren a ladicha villa de Chinchilla $e$ a su termino qualquier cosa a vender o conprara asy los moros e moras del marquesado como los de fuera del marquesado que den e paguen el derecho del 
alquilate de todas cosas que vendieren o conpraren que es de doze maravedis un maravedi e den e pagen deste respleyto segun mas o menos e que aya dello segun dicho es

Otrosi pagan gineta e togese desta guisa de bestias que $f^{f 14}$ vienen cargadas $\mathrm{e}$ pasan de Chinchilla pagan de bestia mayor un comado e por bestia menor un sueldo e sy vinieren bestias cargadas a la villa deChinchílla e se tomasen de ally porque vendan ally el pan e las otras mercadurias que tragieren e pagan de la mayor dos cornados e de la menor dos dineros e sy veniere vazias e pasan de la villa adelante pagen peaje en esta gisa, de la bestia mayor dos cornados e de la bestia menor dos dineros en desto la gineta como dicho es.

Otrosi en razon de las cosas movida que se van las personas de unos lugares a otros, ordeno el dicho señor Marques que non pagen cosa movida sy non fuere en una lugar en todo el Marquesado en el primero que llegare e les fuere demandado la dicha cosa movyda e toman recabdo de como la pagaron porquel dicho recabdo que es alvala lo tienen consigo porque non pagen mas cosa movida en todo el dicho marquesado.

Otrosi ordeno el dicho señor Marques en razon del fecho que se fazen en los dichos lugares e en sus terminos del dicho Marquesado se coge el derecho del dicho almoxarifadgo porque algunas personas fazen encubiertamente algunas vendidas o conpras entre si por absencia del dicho almoxarifadgo e el dicho almoxarife que esto $f$ ovier de aver e de recabdar oviere sospecha que van vendidas o conpradas o apalabradas o conpradas algunas mercadurias o bestias o ganados menudos o gravados o tras cosas a ome de quien el deve almoxarifadgo della, que le faga jura que non van vendidas nin conpradas nin apalabradas nin presçio alguno fecho en ellas e faziendo la dicha jura aquel que la oviere de fazer que por lo que jurase que sea quanto o condepnado e la jura que la faga asy el vezino como el barrano porque deste fecho se sepa laverdad.

Otrosi en razon de las farpilleras de la moneda que pagan los mercaderes e otras personas de lo que meten de Aragon en Castilla e sacan de Castilla en Aragon para traer mercadurias e otras cosas que lievan moneda e traen moneda en la manera que dicha es, que dence pagen al millar de la moneda de los comados e de los realengos moneda de Aragon a siete maravedis e medio por cada un millar e de moneda de novenos menudos que non fagan ninguna casa e de las doblas de oro castellanas como moriscas que den por cada una dellas dos comados e de los florines que den e pagen por cada uno dos dineros de la moneda de los reales de plata e de la otra moneda que agora se husa e handa por Castilla que den e pagen por ella al respleyto e al presçio de la moneda de los cornados e sy por aventura otra moneda alguna de ay adelante fuere fecha en Castilla asy deoro como de plata o de otro metal que page por ella al respleyto de las monedas sobre dichas $/{ }^{16}$ Otrosi todas aquellas personas que ganado alguno pasasen Aragon o para otra parte por la villa de Chinchilla e por su termino que den e paguen por cada una cabeça de ganado vacuno de portadgo tres maravedis e por cabeça de puerco o de puerca por cada uno por cada una cabeça un maravedi e de ganado menudo que de e page por cada una cabeça tres dineros e pagan mas gyneta syn esto de cabeças de ganado arriba que sea mayor que sea menor una res de qualquier ganado que sea de çien cabeças de ganado vacuno de cada una cabeça dos cornados e de puercos e de puercas de cada uno por cada cabeça un cornado e de ganado menudo cabrio e lanar de cada uno por cada una cabeça un dinero. 
Otrosi han de pagar los ganados que entraren de los lugares quel dicho señor Marques ha en el regno de Murçia en tierra de montadgo de cada millar tres reses e borra e asadura e dende en adelante deste respleyto

Otrosi en fecho de los çensales de cada lugar pertenesçe al almoxarifadgo e en fadiga e loysmo e faze por la heredad e posesion que lo faze es la posesion e eredad que lo faze es del almorxarifadgo.

Estos dichos çensales son escriptos en cada lugar e que es lo que ha de pagar cada uno e como e en que manera e en que tienpo.

$f^{17}$ Otrosy por aventura el almoxarifadgo demandase el çenso al que lo oviere a dar e que lo non quisiere pagar e el almoxarife pusiere una señal en la heredad que fiziere el dicho çenso e despues que fuere puesta la señal en la dicha heredad por el dicho almoxarife como dicho es el señor de la dicha heredad o el que su mandado entrase en ella ante que aya pagado el dicho çenso pierda laheredad e es del almoxarifadgo.

Otrosi sy entraren bueyes o vacas o yeguas a los lugares del marquesado del reyno de Murçia e a sus terminos por los enbargar asy de Aragon como de Castilla que pagen de erbaje por cada una cabeça soldariega un maravedi e sy los del marquesado del Obispado de Cuenca entraren con semejantes ganados de los sus dichos en termynos de los dichos lugares del Marquesado del regno de Murçia han depagar por ellos de la manera sobre dicha.

Otrosi an de pagar de ganado menudo de los que los susodichos metieran a erbajar en los termynos de los dichos lugares del Marquesado del regno de Murçia erbaje que es por cada ... de ganado menudo quatro sueldos de reales de Valençia e dende arriba todo el ganado que fuere que page por ello a este respleyto e esto que sea por un año e este dicho que lo den e pagen luego sy quier ende con el todo el dicho año quier non.

Otrosi dicho erbaje que lo non paguen sy non en un lugar el primero que llegaren con el dicho ganado e que puedan $/^{P 18}$ andar con el dicho ganado que desta gisa fuere erbajado por todos los termynos de los lugares del dicho Marquesado del regno de Murçia syn pena alguna que non sean tenudos de pagar e dar por ellos mas de un erbaje como dicho es salvo en los lugares donde oviere a pagar por los dichos ganados e asadura, que la paguen.

Otrosi si qualquier persona que algunos ganados de los sobre dichos metiere en los termynos de los sobredichos lugares o de qualquier dellos syn pagar por ellos los dichos derechos de la manera que dicha es, quel almoxarife que cogiere los dichos derechos en lugar e termino donde entraren los dichos ganados de la manera que dicha es que los puedan quitar e este quanto que sea del almoxarifadgo.

Otrosi qualquier persona de qualquier ley o estado o condiçion que sea en Chinchilla conpraren e vendieren cavallos o armas o en su termino que pagen por ello veyntena que es de veynte maravedis un maravedi e sy moro o mora los vendiere o conprare que pagen que es el su derecho de doze maravedis un maravedi e deste respleyto segund mas o menos porque sea entendido que aya regno de lo que los sobredichos desta gisa vendieren o conpraren.

Los de tierra del rey otrosi de Aragon e de los lugares quel dicho señor ha en el Obispado de Cuenca que entraren con sus ganados en los termynos de los lugares $/ \mathrm{f}^{\circ 99}$ dicho señor Marques ha en el regno de Murçia han de pagar montadgo por ellos del primero millar de reses e otra res de asadura e mas en Chinchilla e en su termyno el derecho de la gineta de çiento arriba una res e de çiento abajo, un 
dinero por cada una cabeça otro dinero de asadura fasta en cabeça de çiento cabeças arriba una res e de quantos millares de ganado fueren an de pagar al respleyto de reses por cada millar segund mas o menos, el qual dicho montadgo se paga desta gisa en Chinchilla con un montadgo en todo el rio de otro montadgo, en Fellyn e en e en otro montadgo en Almansa e en Yecla otro montadgo o que lo non den nin paguen sy non una vez en qualquier lugar de los sobredichos que lieven alvala del almoxarife de lo pagaron porque lo non paguen nin que lo demanden mas.

Otrosi en fecho de las varas de los paños de fuera de la tierra del Marques que esta ordenado por carta de son Juan, la qual dicha carta esta en Villena.

Otrosi sea entendido que qualquier que non pagare los dichos derechos segund dicho es e se pasare del lugar syn los pagar, pierdalo todo por descaminado asy las bestias como las mercadurias e otras cosas que van en ellas, salvo el derecho de la gineta que el que se va con el syn lo pagar que lo paga doblado e las costas que fyzieren en yr en pos de los que se van syn pagar el $f>0$ de la dicha gineta.

Otrosi los que pagaren por Chinchilla recueros o mercaderes e otras personas con sus mercadurias e otras cosas e non pagaren el portadgo dellas en Chinchilla e en Almansa, los almoxarifes de Almansa tomaren syn alvala de como non pagaren el derecho del portadgo en Chinchilla pierdalo todo por descaminados e este descaminamiento son las dos partes del de los almoxarifes de Chinchilla e la otra parte es de los almoxarifes de Chinchilla e la otra parte es de los almoxarifes de Almansa e si los semejantes destos pasaren por Almansa fueren an pagar el derecho del portadgo en Almansa que fueren a Chinchilla e syn alvala de los almoxarifes de Almansa que el almoxarife de Chinchilla que a estos a tales que los tomen por descaminados las bestias e lo que levaren en ellas e en estas e que deste descaminado que sean las dos partes del almoxarife de Almansa e la otra parte del almoxarife de Chinchilla.

Otrosi que el que pasare ganados de qualquier manera o bestias de silla o de alvarda o de las que dichas son e non pagaren el portadgo dellas segund dicho es que lo pierda todo por descaminado e esto que sea tanbien por sabida como por tomada

$f^{f^{21}}$ Otrosi que ninguno nin alguno non pueda yr por el camino murçiano nin por los caminos de nin por otro camino nin por fuera de camino sy non fuere por los caminos reales acostunbrados e tanpoco los que son francos como los que non son francos que an de oagar algund derecho de los que dichos son e los que son francos deven e sean tenudos de yr mostrar su franqueza e vezindad que han al almoxarife del lugar e sy lo non mostrare como dicho es que sean tenudos de pagar el portadgo de lo que levaren e qualquier que por estos dichos caminos fuere sy non fuere por los dichos caminos reales como dicho es acostunbrados e asy los francos como los que non son francos que pierdan quanto levaren por descaminado e sea del almoxarifadgo.

Otrosi los ganados que han de pagar almoxarifadgo an de venir por los caminos reales acostunbrados que van de Chinchilla a Almansa e a Yecla por los dichos caminos que dichos son e non vayan con ellos por otro camino nin por fuera dellos nin por otra parte alguna e sy por otra parte fueren con ellos e los levaren pierdanlo todo por descaminado e este es tanbien por sabido como por tomada e es del almoxarifadgo.

Otrosi el ganado vacuno an de venir con ello por las veredas e non por los caminos reales por con liçençia de los almoxarifes esto por razon de las aguas de de 
los pastos por quanto el ganado $f^{P} 22$ vacuno es ganado que se non puede meter en logares estrechos porque non faga daño e mal en panes e en viñas e si de otra gysa fueren e los levaren syn liçençia de los almoxarifes como dicho es que lo pierda todo por descaminado e esto que sea asy por sabida como por tomada e es del almoxarifadgo.

Otrosi los que sacan pan Aragon han de pagar de cada un dinero asi de perdizes como de conejos e del tres maravedis e de ellos dos maravedis e del cabrio montes dos maravedis e de la cabra montes quatro dineros e del puerco javaly tres maravedis e de la puerca javaly dos maravedis e el que esto sacare es tenido de lo venir a dezir e mostrar e manifestar e pagar el derecho sobre el dicho dello al almoxarife que estudiere en los dichos lugares acostunbrados e non por otra parte e ci que esto non fiziere e lo non guardara que la carga que levare e los venados e las bestias en que lo levare si de otra guisa lo levare e por otra parte lo pierda todo por descaminado e esto que sea asy por sabido como por tomada e esto esto del almoxarifadgo.

Otrosi sea entendido que en razon de los que sacaren Aragon ganados mayores e menores e muletos e muletas e de alvardas e asnos e asnas e mulos e mulas de silla e moros e moras e tartaros e tartaras e caça e venados $f^{23}$ todos han de pagar por ellos los dichos derechos asy los que son francos en el Marquesado como los que non son francos asy del Marquesado como de tierra del rey e de ordenes e de señorios como de tierra de Aragon e de otras partes asy de los que sacasen de las dichas cosas de Castilla Aragon como los que metieren de las dichas cosas de Aragon en Castilla.

Otrosi sea entendido en fecho como se a de usar y los que por y pasen derechos a Chinchilla que non han depagar derecho alguno e que los que pasaren por el dicho lugar contra Requena o contra otras partes e conpraren e vendyeren en el dicho lugar e si termino algunos cosas de que deven pagar los dichos derechos que den e paguen aquel o aquellas personas que lo ovieren de dar por aquella regla e forma e uso e costunbre de todas cosas, segund es e esta ordenado como se ha de pagar dellas en Chinchilla e su termino asy de portadgo e erbaje e montadgo e almoxarifadgo e alquilate e gineta e ferias como las otras cosas.

Otrosi en fecho de la sal de las salinas de Fuente Almilla e de Fellin e toda la sal que quedare al arrendador del año pasado a la de tomar todo el arrendador del año que veniere, pagado le $f^{P 24}$ por ello la costa agregada que fizo en razon de la dicha sal.

Otrosi quel almoxarife que toviere las dichas salinas o qualquier dellas que de sal a los lugares donde anda esta dicha sal a seys maravedis la fanega de la dicha sal e que non pueda mas demandar nin levar a los sobredichos e sy la vendiere a otras personas de otras partes o de otros lugares que se la venda como mas quisiere e pudiere.

Otrosi sy por aventura algunos de los que han de tomar sal de las dichas salinas tomaren sal de otras salinas salvo ende de las de Villena e les fuere fallado en casa o en saco pagaren de pena por cada una vegada sesenta maravedis.

Otrosi sy por aventura alguna o algunas de las personas que bon son tenidas de tomar sal de las dichas salinas asy del marquesado como de tierra del rey o deotra parte qualquier pasaren e levaren sal de las salinas de Orihuela o de Jumilla o de otras salinas asy de Castilla como de Aragon que la lieven a vender fasta Castilla o algunos lugares de los que no son tenidos de tomar la dicha sal vendieren sal alguna 
a algunos des- $f^{025}$ tos que traen sal de las dichas salinas de Xativa o de Orihuela o de Jumilla o de otras partes de las que dichas son, que pierdan toda la sal e las bestias en que la troxieren.

Otrosi sy alguna persona o personas de los lugares que son tenidos a tomar sal de las salinas de Villena e de Fuente Almilla e de Fellyn cada uno sobre sy troxiere alguna sal de otras partes o de otras salinas sy non de las que dichas son e el almoxarife que tuviere las dichas salinas o qualquier dellas oviere sospecha que alguna persona o personas oviere traydo sal de otras partes e non de las dichas salinas de las que son tenidos a tomar sal dellas que pueda entrar el dicho almoxarife con un ofiçial de la villa o Jugar do esto acaesciere en las casas o casa o en los que oviere sospecha que oviere o estuviere tal sal e que las pueda catar e escodriñar syn pena e syn caloña e los señores de las casas o casa de quien el dicho almoxarife oviere tal sospecha que ge las dexen catar e esto de pena de cien maravedis a cada uno e sy tal sal fallare en qualquier casa o casas, que la fallare e por cada una vez que la fallare que le caya en pena a cada uno de seysçientos maravedis e estas penas sobredichas son del almoxarifadgo.

Otrosi ordeno el dicho señor Marques de las asaduras, las dichas asaduras eran dantes del almoxarifadgo e agora es merçed del señor Marques que en lugares donde oviere alcaydes que la tome e aya el alcayde e en los lugares que non ovieren $f^{\prime 2}$ alcayde que las asaduras que sean del almoxarife.

Otrosi han de pagar los de tierra de el portadguillo en esto es porquel dicho portadguillo es e pertenesçe al almoxarifadgo de Chinchilla.

Otrosi el derecho del almoxarifadgo que pertenesçe a las ferias que se fazen en Chinchilla de las cosas que pertenesçen a se pagar en ellas del dicho almoxarifadgo es esto que se sigue. Primeramente el derecho del paso que de como lo cogen el conçejo entre el año en las feryas es del almoxarifadgo e se paga doblado e de las cosas que paran tyendas pagan por cada una tyenda maravedis e de toda legunbre e vellotas e nuezes e de azeytunas e de castañas e de avellanas e de todas otras cosas semejantes destas pagan de cada carga un çelemin e de las frutas asy como fygos verdes e duraznos e peras e uvas e otras qualesquier frutas e semejantes destas non se paga derecho alguno dellas e del derecho del vino que viene a las dichas ferias e a qualquier dellas este derecho es del alguazil de las dichas ferias.

Otrosi la tableteria de las dichas ferias de Chinchilla es del almoxarifadgo.

Otrosi qualquier que pelea en las dichas ferias o fuere uno a otro en qualquier manera que sea a de pagar cada uno seysçientos maravedis $f^{p 27}$ depena al almoxarifadgo por cada una vez

Otrosi qualquier que jugare a los dados fuera del tablero de la tablajeria de las dichas ferias o de qualquiera dellas que fuere puesto por el almoxarife a de pagar de pena por cada una vez sesenta maravedis e de noche la pena doblada fallando los juogando e el señor de la casa donde jugaren que los acogieren a jugar que cayga en pena de dia por cada una vez sesenta maravedis e de noche que aya la dicha pena doblada por cada una vez, que son del almoxarifadgo.

Otrosi qualesquier bestias o bueyes o vacas o ganados menudos que se pasaren por vender en las dichas ferias de Chinchilla en qualquier dellas non an de pagar por ellas pasada nin otro derecho alguno salvo la gineta.

En Almansa e su termino se coge e a de coger el derecho del dicho almoxarifadgo desta guisa, primeramente de portadgo de los paños e espeçeria, buhoneria c ajos e vinagre e seda algodon asoge molida toda adobada paga todo esto por es a saber 
carga menor quatro maravedis e carga mayor seys maravedis e cueros pagan por medio carga mayor tres maravedis e por carga menor dos maravedis e de tierra de Manises, es quesoo o e lana e lino e alfonbras e tapetes $f^{p 28}$ e filasa e alfeña e xabon e esteras e palmitos e pastel e tyntas e pasa e figos secos e pescado salado e congrio e sardina e arroz e limones todas estas cosas semejantes destas pagan todas por castellano es a saber por carga menor quinze dineros e por carga mayor dos maravedis e por carga e de vyno pagan por carga valady que es de la carga menor siete dineros e medio e de la carga mayor un maravedi.

Otrosi quando el rey faze algund pan Aragon paga de vaca el que lo saca a el almoxarife por cada un cafiz tres maravedis en esto que pagen asy los francos como los non francos e sy lo non faze que lo pierda por descaminado.

Otrosi han de pagar portadgo decada paño que por sy vaya quatro cornados e los paños que por sy vaya de cada uno quatro cornados e de cada arrova de pimienta un maravedi e de cada arrova de açafran dos maravedis e de pimienta demedia arrova çinco dineros e de media arrova de açafran un maravedi e de todas las otras cosas menudas seste respley to e segund mas o menos.

Otrosi qualquier que pasare a vender Aragon o a Villena muletos o muletas por Almansa e su termyno e los sacare de Aragon a Castilla que el que lo $f^{29}$ sacare que page el diezmo de cada uno de quanto valiere, e sy lo non viniere a manifestar e a dezir al almoxarife de Almansa por le pegar el dicho derecho que lo pierda por descaminado e que lo pierda asi por sabida como por tomada e que sea del almoxarifadgo.

Otrosi qualquier que sacare e pasare a vender en Aragon o en Villena o lo sacare o traxiere de Aragon a Castilla por lo vender o conprar asy roçines de silla como de alvarda asy mulos e mulas de silla como de alvarda asy yeguas como potros, asy asnos como asnas que den e pagen el diezmo dello de quanto les costo o fuere estimado por omes buenos quanto valia cada bestia asy de las conpradas como de las otras que por este puente de Almansa pasaren por vender o por conprar o por su termino e sy la persona que tales bestias traxiere e pasare por el puesto e lugar de Almansa o por su termino lo non fiziere saber o dixiere al almoxarife de Almansa e le non pagare el derecho dellas segund dicho es que lo pierda todo pos descaminado asy por sabida como por tomada e que sea del almoxarife e que en esto que sea entendido que han de pagar este dicho derecho destas bestias sobredichas e de los muletos como de las muletas asy todos los del Marquesado de Villena de los logares del reyno de Murçia los que son francos como los que non son francos que tanbien los de Almansa e de todas las otras villas e çibdades e logares de Castilla como de Aragon qualesquier personas que tales bestias o mulas o muletos pasaren $f^{3}$ por este dicho lugar de Almansa e su termino de la manera que dicha es.

Otrosi qualquier moro o mora que por Almansa e su termino pasaren o pasase o pasan asy de Castilla Aragon como de Aragon en Castilla e levare e traxieren de Villena que den e pagen por cada uno una dobla de oro morisca de desferrar e otra dobla de oro morisca de portadgo e mas syn esto el diezmo de la porque se rindiere e eso pagen de los e sy algunas personas las quisieren levar o pasar furtadas o ellos por sy se fazen por non pagar los dichos derechos e lo non fixiere saber o dixere al almoxarife de Almansa que los pierda e sean perdidos por descaminados e sean del almoxarifadgo e esto que sea tanbien por sabida como por tomada.

Otrosi el almoxarifadgo se paga en Almansa e su termino desta gisa e manera que se usa coger e coge de todas quantas cosas en el dicho lugar de Almansa e su 
termino se vendieren e conpraren asy cavallos como armas e mulos e mulas e muletos e muletas e asnos e asnas e yeguas e potros e roçines e mulos e mulas de alvarda e toda natura de bestias e moros e moras e tartaros e tartaras e todo catyvo e paños e espeçeria e buhoneria e lena e lienços e filasa e todas otras cosas de mercadurias de qualquier natura que sean e se vendieren e conpraren ay en Almansa e sa termino de la manera que dicha es e que $P^{31}$ den e pagaen de todo esto de lo que se vendiere o conprare veyntena que es de veynte maravedis uno por los que vendiere e conprare las dichas mercadurias e otras cosas de las que dichas son, que ayan requento dello porquel almoxarife que se atenga a lo que mas quisiere por que en esto sea entendido que de todas quantas viandas en Almansa se vendieren por menudo por pro e provecho e mantenimiento de la villa de Almansa e de los que moran e byven e estan en ella que los que tal vianda vendieren en la dicha villa de Almansa de la manera que dicha es asi cristianos como judios e moros que non sean tenidos de dar ni depagar derecho alguno por la dicha vianda que desta guisa vendieren en el dicho lugar de Almansa e sy ayuntadamente vendieren los sobredichos o qualquier dellos en la dicha villa de Almansa por levar fuera della que el ome o persona o barrano o barranos que tal vianda conpraren o vendieren dieran para lebar fuera como dicho es que pagen veyntena de lo que desta guisa vendieren conpraren segund dicho es e sy vendieren e conpraren segund dicho es e sy lo non venyeren dezir e manifestar el almoxarife de Almansa e quisieren furtar los dichos derechos de la dicha veyntena, que lo pierdan todo por descaminado e sca todo del almoxarifadgo e esto que sea tan bien por sabida como por tomada.

Otrosi los moros e moras asi los del marquesado como los de fuera del marquesado que algurra cosa de las sobredichas traxieren a vender o comprar en Almansa e su termino en qualquier manera sy bestias no fueren que los de fuera del regno los moros e moras $F^{32}$ quetraxieren a vender bestias algunas a Almansa e su termino de las que dichas son tenidas de pagar diezmo de ellas de la quantia que costaren a las de vender o conprar e de las otras cosas e mercadurias que dichas son todos los moros e moras, asy los del marquesado como los de fuera del marquesado como otros donde quier que sean aunque sea de ay de Almansa que den e pagen el derecho de alquilate por ello que es de doze maravedis un maravedi de todo quanto vendieren e conpraren segund mas o menos a este respleyto e esto que sea tanbien por sabida como por tomada.

Otrosi los que pasaren por este puerto e lugar de Almansa de Aragon a Castilla e de Castilla en Aragon o Villena o pasaren de Yecla por aqui por Almansa fasta Alpera de los que ovieren de pagar los dichos derechos o vinieren o fueren fasta Fellyn o fasta otra parte con bestias varias que den e pagen de las bestias mayores dos cornados e de la bestia menor dos dineros.

Otrosi en razon de las cosas movidas que se van las personas a morar de unos lugares a otros, ordeno el dicho señor Marques que non den nin paguen cosa movida los que desta gisa se fueren sy no fuere en un lugar en todo el Marquesado en el primero logar que liegaren e les fuere demandado la dicha cosa movida e tomen recabdo de como la pagan ay porquel dicho recabdo que es alvala la lieven consigo porque non pagen mas cosa movida en todo el su marquesado e el que quisiere furtar por non pagar el derecho de la dicha cosa movida que lo pierda todo quanto levare por descaminado.

$f^{P 3}$ Otrosi ordeno el dicho señor Marques en razon de que se fazen en los dichos lugares e en sus terminos del dicho su marquesado donde se coge el derecho 
del dicho almoxarifadgo porque algunas personas fazen encubiertamente e encobrir el derecho del dicho almoxarifadgo e el almoxarife que esto ovier de aver e de recabdar ovier sospecha que van vendidas o conpradas o apalabradas algunas mercadurias o bestias o ganados menudos o granados otras cosas o personas de que en el deve al almoxarifadgo que le faga fazer jura que non van vendidas nin conpradas nin apalabradas ni presçio alguno fecho algund en ellas e faziendo la dicha jura aquel que la oviere de fazer que por lo que jurare aquel que la oviere de fazer $o$ por lo que pasare que sea quanto o condepnado e que la jura que la faga asy el vezino como el barrano porque deste fecho se sepa la verdad.

Otrosi en razon de las dela moneda que pasan los mercaderes e otras personas de la moneda que meten de Aragon en Castilla e sacan de Castilla en Aragon por traer mercadurias e otras cosas que levan e traen moneda en la manera que dicha es que den e pagen del millar de la moneda de los cornados e de los realengos de Aragon e siete maravedis e medio por cada un millar e de la moneda de los menuda que non den nin pagen ninguna nin alguna cosa por ella e de las doblas de oro asy castellanas como moriscas que den e pagen por cada una dobla dos comados e de los florines que den e pagen $f^{34}$ por cada uno dos dineros e de la moneda de los reales deplata, que den e pagen por millar al respleyto dela moneda de los cornados de cada millar de los reales veynte e dos maravedis e medio e a este respleyto segund mas o menos e sy por aventura otra moneda alguna de aqui adelante fuese fecha o se fiziere en Castilla asy de oro como de plata o de otro metal, que den e pagen por ella al respleyto de las monedas sobredichas e sy alguno quisiere o quisiese que non leva moneda alguna o que dixiere que non leva tanto como manifiesta e fuere sabido o tomado que leva moneda alguna mas de quanta manifiesta o perjura de el que la levare la dicha moneda o por pena o por otra cosa alguna que pierda toda la moneda que non manifestare asy por sabida como por tomada e sea del dicho almoxarifadgo.

Otrosi todas aquellas personas que ganados algunos pasaren de Castilla a Aragon o de Aragon a Castilla e a Villena por esta villa de Almansa e por una cabeça de ganado menudo dos dineros e deganado vacuno por cada una cabeça tres maravedis e por cada una cabeça de puerco o de puerca un maravedi porque los que estos dichos ganados pasaren o traxieren de la manera que dicha es que los traygan por el camino dicho con ellos real que viene de Chinchilla a Almansa e non sean osados de yr con ellos por otros caminos nin por el de Alpera nin por el de nin $t^{\circ} 35$ por otro camino alguno nin por fuera de camino e sy lo fiziere que sean perdidos por descaminados e que sean del almoxarifadgo de Almansa esto se entyenda tanbien por sabida como por tomada.

Este dicho derecho deestos dichos ganados e bestias e caça los han de dar e de pagar asy los de los lugares que son francos como los que non son francos.

Otrosi han de pagar los ganados que entraren de los lugares del dicho marquesado quel dicho señor Marques ha en el regno de Murçia en tierra de, de montadgo decada millar tres reses e borra e asadura dende adelante, a este respleyto.

Otrosi si entraren bueyes o vacas o yeguas a los lugares del Marquesado del regno de Murçia e a sus terminos por los erbajar asy de Aragon como de Castilla que den e pagen de erbaje por cada una cabeça soldariega un maravedi e sy los dichos lugares del Marquesado del Obispado de Cuenca entraren con semejantes ganados de los sobredichos en los terminos de los lugares del Marquesado del regno de Murçia, han de pagar e an de dar por ello de la manera sobredicha. 
Otrosi han de dar e de pagar de ganado menudo delo que los susodichos metieren e erbajar en los terminos $f^{\mathrm{P}} 36$ de los dichos lugares del marquesado del regno de Murçia por cada cabeças de ganado menudo quatro sueldos de reales de Valençia e dende arriba que todo el ganado que fuere que den e pagen deste respleyto e esto que sea por un año e este derecho que lo den e pagen luego e sy quier, anden con el dicho ganado todo el año sy quier non.

Otrosi este dicho erbaje que lo non den nin pagen sy non en un lugar al primero que llegaren con el dicho ganado e que puedan andar con el dicho ganado que desta gisa fuere erbajado por todos los terminos de los dichos lugares del dicho Marquesado del regno de Murçia syn pena alguna e que non sean tenidos de dar por ellos mas de un erbaje como dicho es, salvo en los lugares donde oviere de dar e depagar por los dichos ganados borra $\mathrm{e}$ asadura e puente que la pagen.

Otrosi qualquier persona que algunos ganados de los sobredichos metiere en los dichos terminos de los dichos lugares o de qualquier dellos syn pagar e dar por ellos el dicho derecho de erbaje e como dicho es que el almoxarife que cogiere los dichos derechos en el lugar e termino donde entraren con los dichos ganados de la manera que dicha es e que los pueda quitar e este quanto que sea del almoxarifadgo del lugar donde fuere tomado.

Otrosi los de tierra del rey e de los lugares que el dicho señor Marques ha en el Obispado de Cuenca que entraren con sus ganados en los terminos de los lugares que el dicho señor Marques ha en el regno de Murçia an de dar e depagar de $f^{P} 37$ montadgo por ellos del primero millar reses e mas otra res de asaduras e de quantos millares deganado fueren an de dar e de pagar al respleyto de reses por cada millar segund mas o menos el qual dicho montadgo se paga desta gysa, en Chinchilla con un montadgo en todo el rio de otro montadgo en Almansa e en Yecla otro montadgo en Fellyn e Tovarra otro montadgo asy que desta manera se a de dar e de pagar el dicho montadgo.

Otrosi porque las vacas e bueyes e novillos e ganado bravio e los quantos que con ellos no pueden venir por el camino real que es de Chinchilla aqui Almansa segund vyene e an de venir todos los otros ganados menudos e se uso sienpre que los que traen los dichos ganados vacunos los traen por vete e por termino de Alpera esto por razon de los pastos e de las aguas que ayan para los dichos ganados e otrosi porque non fagan por ellos dapño e mal en los panes e en las viñas, es que an de venir con ellos por estos caminos e veredas que es dicho camino e senda de las vacas que los dichos ganados vacunos se uso sienpre venir por los dichos lugares por lo que dicho es e aun que los dichos ganados no entren con ellos en termino de Almansa los quales han devenir al dicho lugar Almansa e defazer saber al almoxarife de Almansa en como ellos traen tanto ganado vacuno por los dichos lugares que dichos son e deven le pedyr e demandar liçençia que los dichos ganados vacunos levar por los dichos lugares por do an uso e costunbre de los levar e esto por ellos fecho el almoxarife de Almansa $l^{38}$ les deve dar su liçençia que lieven o traygan los dichos ganados vacunos por los dichos lugares aunque non entren con ello en termino de Almansa e pues lo an asy de uso e de costunbre e la liçençia dada por el almoxarife de Almansa a los que traxieren los dichos ganados vacunos de la manera que dicha es que los que levaren los dichos ganados por los dichos lugares que los lieven e traygan con alvala del almoxarife de Almansa e con su liçençia que los puedan levar e traer por los dichos lugares sin pelygro alguno, ello pagando los que los dichos ganados traxieren almoxarife de Almansa por cada una cabeça del dicho 
ganado vacuno tres maravedis e quien de otra gisa lo fiziere e se quisiere yr o fuere con sus dichos ganados por los dichos lugares o por otra parte syn fazer lo que dicho es por furtar e menguar el dicho derecho del dicho ganado como dicho es, que pierda todo el ganado por descaminado e que sea del almoxarifadgo e esto que sea tanbien por sabida como por tomada.

Otrosi en fecho delos çensales de cada lugar, pertenesçen al almoxarifadgo e han fadiga e diezmo e sy non pagaren el çenso en tres años el que lo faze por la heredad que lo faze es e la posesion e heredad porque lo faze es perdida e es del almoxarifadgo.

Estos dichos çensales son escryptos en todo logar donde se faze que es lo que an de pagar cada uno e como e en que manera e en que tienpo.

$f^{39}$ Otrosy sy por aventura el almoxarife demandase el çenso al que lo oviere de dar al tienpo que ge lo oviere a dar equanto no quisiere dar nin pagar e el almoxarife pusiere una señal en la heredad que fiziere el dicho çenso e despues que fuere puesta la dicha señal en la dicha heredad por el dicho almoxarife como dicho es e el señor de la dicha heredad o otro por su mandado entrare en ella ante que aya pagado el dicho zenzo pierda la heredad e es del almoxarifadgo.

Otrosi en fecho de las varas delos paños de la tierra del señor Marques cogiere segund que esta escrypto e ordenado por carta de don Juan, la qual dicha carta esta en Villena.

Otrosi sea entendido que qualquier que non pagare los dichos derechos segund dicho es de todas las cosas sobredichas e de cada una dellas segund su natura que es cada una e se pasare del lugar syn las pagar, pierdalo todo por descaminado asy las bestias como las otras cosas que van en ellas como dicho es e son del almoxarifadgo.

Otrosi sea publico e manifiesto a toda persona de qualquier estado o condiçion o ley que sean que non sean osados de llevar las dichas cosas como mercadurias e ganados menudos e granados e todas bestias de las que dichas son e otras cosas qualesquier de qualquier natura e moros e moras e tartaros e tartaras por otra parte alguna sy non fucre por los caminos reales que dichos son e sy los levaren por otros caminos o por $f^{\mathrm{P}} 40$ otras sendas que non ayan lugar ni razon de las levar ni tanpoco nin menos fuera de los dichos caminos reales por donde no oviere camino que el que esto fizyere que todo quanto desta gisa levare que lo pierda todo por descaminado e sea del almoxarifadgo e esto que sea tanbien por sabida como por tomada.

Otrosi los que pasaren por Chinchilla recueros o mercaderes o otras personas con sus mercadurias e otras cosas e non pagaren el portadgo dellas en Chinchilla e en Almansa los almoxarifes de Almansa a estos tales tomaren syn alvala de como non pagaren el derecho del dicho portadgo en Chinchilla pierdanlo todo por descaminado e deste descaminamiento son las dos partes de los almoxarifes de Chinchilla e la otra parte es de los almoxarifes de Almansa e sy los semejantes destos pasaren por Almansa e se fueren syn pagar el derecho del portadgo de Almansa e se fuesen a Chinchilla syn alvala del almoxarife de Almansa que el almoxarife de Chinchilla que a estos tales que los tome por descaminados las bestias e todo quanto levaren en ellas o omes a cuestas e que este descaminamiento que sea las dos partes del almoxarife de Almansa e la otra parte del almoxarife de Chinchilla.

Otrosi que sea declarado e entendido que ninguna nin alguna persona asy los que francos como los que non $f^{41}$ francos asy los del marquesado como los de fuera del marquesado asy del reyno de Castilla como del reyno de Aragon e de otros 
reynos o de otras partes non sean osados de yr nin llevar nin de traer las dichas cosas e bestias e mercaderias e ganados de todas quantas en este ordenamiento se contyenen de moros e moras e tartaros e tartaras sy non fuere por el camino real o reales acostunbrados e non por otro caminos encubiertos nin por sendas nin por fuera de camino e qualquier de los sobredichos asy los francos como los non francos que alguna de las dichas cosas llevaren fuera de los dichos caminos reales por otros caminos o por otras partes como dicho es, que lo pierda todo por descaminado e que sea todo asy las bestias como las otras cosas del almoxarifadgo e esto que sea tanbien por sabida como por tomada $\mathrm{c}$ los dichos lugares que son francos que sean tenudos de mostrar en cada lugar su franqueza e su veçindad de como son francos del almoxarife de cada lugar e sy esto non fizieren aunque sea conosçido que mora e esta en lugar franco que page el portadgo de todo quanto levare.

Otrosi los que sacan caça a Aragon o a Villena an de dar e de pagar por ello por cada un par un dinero asy de perdiçes como de conejos e del tres maravedis e de la dos maravedis e del cabrio montes dos maravedis e de la cabra montes quinze dineros e del puerco javali tres maravedis e de la puerca javali dos maravedis $f^{\mathrm{T}} 42$ e el que esto sacare a lo de sacar por los puertos acostunbrados los quales son Almansa e Yecla e Alcala del Rio de e non sean forzados de los levar e pagar por otros lugares nin por otro caminos e los que esto sacaren que sean tenidos de lo venyr dezir e manifestar e mostrar e pagar el dicho derecho de lo sobredicho al almoxarife que fuere o estuviere en los dichos lugares o en qualquier dellos por donde quisiere levar e pagar la dicha e que non osen nin sean osados de la levar por otras partes nin por otros lugares sy non por los que dichos son, sy yr non fuere con voluntad e liçençia de los dichos almoxarifes o de qualquier dellos que lo pierda todo por descaminado asy la carga como las bestias en que lo lieva e que sea todo del almoxarifadgo e esto que sea tanbien por sabida como por tomada.

Otrosi ordeno al dicho señor Marques del fecho de las asaduras las dichas asaduras eran de ante del almoxarifadgo e agora es merçed del dicho señor Marques que en los lugares donde non oviere alcaydes que sea del almoxarifadgo e en los lugares donde oviere alcaydes que las tome e aya el alcayde.

Otrosi el derecho del almoxarifadgo que pertenesçe a las ferias que se fazen en Almansa de las cosas que pertenesçe a se pagar en ellas al dicho almoxarifadgo es esto que se sige.

$f^{43}$ Prymeramente las tyendas que en las dichas ferias o en qualquier dellas se pararen asy de paños como de espeçeria e buhoneria e esmerçeria e de lienços e de sayales e de otras cosas semejantes que en las dichas ferias o en qualquier dellas se pararen, que den e pagen de parada por cada una destas cosas de parada doze maravedis e de parada de quatro maravedis sy ganados algunos mayores e menores o bestias de las que dichas son o armas o otras mercadurias que se pararen a vender en las dichas ferias o en qualquier dellas que non den ninguna veyntena dellas nin los moros nin moras, salvo sy algund moro o mora o tartaro o tartara se rindiere o rindiese en las dichas ferias o de qualquier dellas que den e pagen todo su derecho del diezmo por lo que se vendiere o rindiere e mas syn esto. una dobla del desferramiento e otra deportadgo e mas las tyendas que se pararen de vellotas e de castañas e de avellanas e de almendolas e de azeytunas e de nuezes e deotras cosas semejantes destas, que den e pagen por cada una carga, un çelemin deste respecto. segund mas o menos. 
Otrosi, qualquier que pelea en las dichas ferias o en qualquier dellas o fyere uno a otro en qualquier manera que sea a depagar cada uno seysçientos maravedis de pena al almoxarife por cada una vez.

Otrosi qualquier que parare entienda un paño solo que pagare de parada por el dicho paño e el que parare $f^{*} 44$ dos paños que page un maravedi e de tres paños, quinze dineros e de quatro paños, dos maravedis e dende en adelante a este respleto de parada.

Otrosi, la tablegeria de las dichas ferias o de qualquier dellas es del almoxarifadgo e qualquier persona que jugare los dados fuera del tablero de la tablegeria de las dichas ferias o de qualquier dellas syn liçençia e voluntad del tablegero, que fuere puesto por el almoxarife, la persona o personas que esto fizieren han de pagar de pena por cada una vez que lo fiziere, seysçientos maravedis e mas el señor de la casa que los acogiere a jugar a estos a tales a la pena doblada de noche de los que jugaren de la manera que dicha es e los que los acogiesen a jugar en sus casas que estos a tales que aya la pena doblada.

En e en Alcala e vez con sus terminos e en todo el rio de usose sienpre coger e se coge todo el derecho del dicho almoxarifadgo segund se uso e coge en Almansa e su termino de aquella misma manera e con aquellas condiçiones mismas porque es todo un almoxarifadgo e una condiçion e por aquel estableçimiento e uso mismo.

En Yecla e su termino usose sienpre coger e se coge todo el derecho del dicho almoxarifadgo segund se uso coger e coge en Almansa e su termino de aquella misma manera e con aquellas condiçiones $f^{\mathrm{P}} 45$ mismas porque es toda una cosa e un almoxarifadgo e una condiciçion e por aquel ordenamiento e estableçimiento e uso mismo que se coge en Almansa e su termino e se ha de coger e coge en Yecla e su termino,

Otrosi en Fellyn e en se uso coger e recabdar e se ha de coger e de recabdar el derecho del dicho almoxarifadgo e desta gisa e manera primeramente de la manera que se dira.

De las bestias que por ally pasaren que vayan varias que cargadas an de pagar de peaje por cada una desta gisa por la mayor bestia dos cornados e por la menor bestia dos dineros.

Otrosi los barranos que en Fellyn e en sus terminos conpran o venden algunas cosas de las que en este ordenamiento e declaraçion se contyene que den e pagen por ellas veyntena que es de lo que conpraren o vendieren de veynte maravedis un maravedi, porque an de requento el almoxarife e se atenga a lo que mas quisiere.

Otrosi en los dichos lugares e sus terminos pagan el derecho de las varas segund esta ordenado por carta de don Juan, la qual carta es e esta en Villena.

Otrosi los moros e moras delos dichos lugares e de cada uno dellos o de fuera de los dichos lugares asy del marquesado como de otras partes asi de Castilla como de Aragon $f^{f t a}$ an de pagar e pagaran sienpre de las cosas que vendieren e conpraren el derecho del el qual derecho es de quinze maravedis un maravedi e a este respeto segund mas o menos segund se contiene en este ordenamiento de las cosas e mercadurias en el contenidas porque los mercaderes e vendedores e conpradores de las dichas cosas an de requento dellas porquel almoxarife que se atenga a lo que el mas quisiere a la conpra o la venta e que esto que sea tanbien por sabyda como por tomada. 
Otrosi pagan e dan mas los dichos moros de Fellyn otro derecho de cada un año que es dicho e llamado el dicho derecho que es de cada una cabeça del moro e de cada casa asy del mayor de casa como la muger e los fijos e otras qualesquier personas que estovieren en la dicha casa que den e pagen cada una persona que estudiere en la dicha casa de la manera que dicha es un çelemin de çevada asy por la chica persona como por la grande.

Otrosi dan e pagan los dichos moros de Feflyn los casados por cada una cabeça seys maravedis e dos cornados e que den e pagen este derecho mismo, asy los moros biudos como las moras biudas an de pagar mas los moros e moras que son de heredad, que den e pagen por cada una cabeça quatro maravedis e dos cornados.

Otrosi an de pagar e dar mas los dichos moros e moras de Fellyn los casados como los buydos e buydas cada uno de cada una casa de cada un año una gallyna.

$f^{\circ}$ Otrosi pagan e dan mas los dichos moros de cada un año de Fellyn e las moras otro derecho que dizen el qual dan e pagan desta gisa, de ganado menudo dequarenta cabeças, una cabeça e mas fasta en e veynte cabeças dos cabeças de dozientas cabeças e dende arryba a este respecto mas de quarenta cabeças non dan nin pagan nada.

De vacas nin de yeguas nin de asnos nin de asnas non pagan ninguna nin alguna cosa e esto por quanto diezman.

Otrosi qualquier moro o mora que cayere en alguna pena por malefiçio que faga que sea judgado por su alcallde de los moros estando el almoxarife presente e sy los açotes fueren o fuesen judgados por el dicho su alcallde contra el dicho moro o mora, los non quisiere aver nin reçibyr, que den e pagen por cada un açote al almoxarife dos maravedis, non queriendo aver nin reçybir los dichos açotes segund dicho es.

Otrosi los ferias de Fellyn son del almoxarifadgo.

Otrasi los que pasaren por Fellyn o por su termyno bueyes o vacas e novillos o potros a yeguas o roçines o muletos o muletas e se vayan a vender que de e page por cada una dellas que se non ayan a vender tres maravedis deportadgo e de los moletos e muletas de silla que den e pagen por cada una, seys maravedis e quien levare $f^{p 48}$ o pasare las dichas cosas e cada una dellas sy non fuere por el camino real o por los lugares acostunbrados o non pagare los dichos derechos que lo pierda todo por descaminado e son del almoxarifadgo e esto que sea tanbien por sabida como por tomada e mas que den e pagen deportadgo delos asnos e de las asnas por cada una, un maravedi.

Otrodi en fecho de las delos moros e moras los que murieren syn herederos algunos los bienes que destos tales que murieren syn herederos desta gisa son e pertenesçen al almoxarifadgo e que sean judgados por el alcallde moro estando sienpre en ello el dicho alcallde de los dichos moros nin los vezinos nin otro moro alguno nin tomar ni entrar los dichos bienes destos tales syn estar presente en ello el dicho almoxarife e sy lo fiziere quien quier que lo faga non estando a ello presente el dicho almoxarife a ello como dicho es, los que esto fizieren asy el dicho alcallde moro como los viejos o otro moro qualquier que ellos e todos sus bienes son $\mathrm{e}$ pertenesçen al almoxarifadgo.

Otrosi si algund moro o mora pusiere querella ante el alcallde moro de otro moro o mora que el que tal querella pusiere que sea tenudo de lo que lo e de que lo levar adelante e si lo non fixier la querella puesta que se pare a la pena el que la 
pusiere dicha querella $f^{\mathrm{P}} 49$ que merezca aver aquel o aquella contra quien fuere o fuese puesta la dicha querella de la cosa que querellase seyendole.

Otrosi qualquier alcallde moro que encubriere o qualquier cosa del derecho del dicho almoxarifadgo es cautivo del almoxarife.

Otrosi en el puerto de Mula, termino de Fellyn el derecho della a se de coger el derecho en ella segund se uso e acostunbro coger sienpre e mas sobre esto el dicho señor Marques por se gerteficar de este fecho a enbiado su cara por saber como se coge este derecho en el dicho puerto de mala como se uso coger sienpre.

En el forno e el molino dende es del almoxarifadgo e pagan en el e en su termino veyntena como en Fellyn e en su termino.

E estos dichos derechos el dicho señor Marques manda e es su merçed e tiene por bien que se coxan e recabden segund esta escrypto e fecho por este su ordenamiento e declarado por el, e sy por aventura algunas otras cosas que son del almoxarifadgo e pertenesçen a el non son escriptas e puestas en este dicho ordenamiento que las den e pagen por aquel derecho e manera e uso e costunbre de las otras que aqui son escriptas e ordenadas los que las ovieren de pagar.

Otrosi que los dichos almoxarifes o qualquier dellos que por sy syn ofiçial pueden encargar las frosadas a qualesquier personas que alguna cosa ovieren de dar e de pagar los dichos derechos que posen asy en ostal que es dicho meson como en otras casas epposadas donde quier que tales ovier e sy los que fueren enbargados por los dichos almoxarifes o por qualquier dellos el ostalero o el mesonero o el otro donde posaren los dexare yr syn lizençya del almoxarife que el que esto fiziere que sea tenido de dar e de pagar al almoxarife do este fuere e acaesçiere todo quanto oviere a dar el que desta gisa fuere o fuese enbargado e que lo den e pagen por descaminado por la osadia que faze en lo dexar yr syn dar e pagar lo que ovier o oviese de dar e de pagar de la manera que dicha es.

Otrosi que todos los pleytos que se acaesciesen de aver en este almoxarifadgo en todos los dichos lugares e en cada uno dellos e sus terminos sobre las cosas que en este ordenamiento e declaraçion son contenidas que los libren e vean qualquier ofiçial de los dichos lugares o de qualquier $f^{P 51}$ dellos que los dichos almoxarifes $o$ qualquier dellos do tales pleytos acaesçieren quisieren e tomaren ello que los libren ellos e esto por tal que luego syn alongamiento de maliçia alguna los dichos pleytos deste dicho almoxarifadgo sean librados entre las partes desenbargadamente e syn tardança alguna.

Otrosi qualquier persona que sea vezina o moradora en las villas e lugares del dicho marquesado los que son francos alguno o algunos vezinos de los dichos lugares, con la franqueza que an levaren o traxieren alguna mercaduria o otra cosa encubierta de alguna o algunas otras partes o de otros lugares que non son francos por furtar el derecho del dicho almoxarifadgo, que el que esto tal fiziere que todo lo encubierto desta gisa que sea perdido todo por descaminado e el que lo levare encubierto con su franqueza o de otra manera que cayga en pena por ello de seysçientos maravedis por cada una vez que lo fiziere e esto que sea tanbien por sabida como por tomada e que esta dicha pena con todo lo otro pertenesçe e es del almoxarifadgo. 